STUDI

FRANCESI

\section{Studi Francesi}

Rivista quadrimestrale fondata da Franco Simone

188 (LXIII | II) | 2019

Penser/peser le Moyen Âge entre XVe et XVIIe siècle:

parcours de recherche - sous la direction de Maurizio

Busca et Piero Andrea Martina

\title{
André Bayrou, Distance et reconnaissance dans l'écriture de soi: le cas des poèmes judiciaires de «L'Adolescence Clémentine» (1538)
}

\section{Filippo Fassina}

\section{(2) OpenEdition \\ Journals}

\section{Edizione digitale}

URL: http://journals.openedition.org/studifrancesi/19612

DOI: 10.4000/studifrancesi. 19612

ISSN: 2421-5856

\section{Editore}

Rosenberg \& Sellier

\section{Edizione cartacea}

Data di pubblicazione: 1 août 2019

Paginazione: 346

ISSN: 0039-2944

Notizia bibliografica digitale

Filippo Fassina, «André Bayrou, Distance et reconnaissance dans l'écriture de soi: le cas des poèmes judiciaires de «L'Adolescence Clémentine» (1538)», Studi Francesi [Online], 188 (LXIII | II) | 2019, online dal 01 février 2020, consultato il 25 janvier 2021. URL: http://journals.openedition.org/studifrancesi/ 19612 ; DOI: https://doi.org/10.4000/studifrancesi.19612

Questo documento è stato generato automaticamente il 25 janvier 2021.

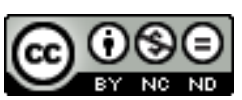

Studi Francesi è distribuita con Licenza Creative Commons Attribuzione - Non commerciale - Non opere derivate 4.0 Internazionale. 


\title{
André Bayrou, Distance et reconnaissance dans l'écriture de soi: le cas des poèmes judiciaires de «L'Adolescence Clémentine» (1538)
}

\author{
Filippo Fassina
}

\section{NOTIZIA}

André Bayrou, Distance et reconnaissance dans l'écriture de soi: le cas des poèmes judiciaires de «L'Adolescence Clémentine» (1538), "Le verger - bouquet XIV" (novembre 2018), en ligne, $14 \mathrm{pp}$.

1 Dal punto di vista letterario, l'utilizzo del concetto di "distanza", intesa come tendenza al nascondersi e al mascherare una verità, è frequente soprattutto in relazione all'ironia con cui un autore affronta tematiche difficili o dolorose dal punto di vista autobiografico. Tale artificio è ancora più evidente in un autore come Clément Marot, considerato un vero e proprio maestro nell'uso della distance, grazie all'umorismo e all'ironia con cui egli affronta gli argomenti più delicati. In particolare, all'interno dell'Adolescence clémentine del 1538, i componimenti relativi alle sue disavventure giudiziarie sono gli esempi più evidenti di questa tecnica, soprattutto se si considera il fatto che si situano nel contesto della repressione religiosa antiriformista, susseguente allo scandalo dei placards, che costrinse il poeta a due anni di fuga dall'Italia. Benché il rischio di incarcerazione sia più che concreto, Marot tratta il suo dramma personale secondo un processo che l'A. definisce di "carnevalizzazione", andando nella direzione di un linguaggio triviale che mette in discussione l'autorità stessa della giustizia. Vengono dunque forniti numerosi esempi di come i dettagli autobiografici, nell'Adolescence clémentine, siano contaminati da una vena satirica finalizzata ad attenuare la gravità degli eventi e a rendere al lettore più piacevole e meno angosciosa la lettura. In questo modo, si instaura un rapporto fra autore e pubblico che permette di 
offrire un'interpretazione più lucida degli eventi proprio perché analizzati in maniera distaccata e dunque più oggettiva. 